\title{
Forecasting imbalances of human resources for health in the Thailand health service system: application of a health demand method
}

Nonglak Pagaiya $^{1 *}$ (D, Pudtan Phanthunane ${ }^{2}$, Adun Bamrung ${ }^{3}$, Thinakorn Noree ${ }^{4}$ and Karnwarin Kongweerakul ${ }^{4}$

\begin{abstract}
Background: For an effective health system, human resources for health $(\mathrm{HRH})$ planning should be aligned with health system needs. To provide evidence-based information to support HRH plan and policy, we should develop strategies to quantify health workforce requirements and supply. The aim of this study is to project HRH requirements for the Thai health service system in 2026. HRH included in this study were doctors, dentists, nurses, pharmacists, medical technicians (MTs), physiotherapists (PTs), and Thai traditional medicine (TTM) practitioners.

Methods and results: The study mainly relied on the secondary data in relation to service utilization and population projection together with expert opinions. Health demand method was employed to forecast the $\mathrm{HRH}$ requirements based on the forecasted service utilizations. The results were then converted into HRH requirements using the staffing norm and productivity. The HRH supply projection was based on the stock and flow approach in which current stock and the flow in and out were taken into account in the projection. The results showed that in 2026, nurses are likely to be in critical shortages. The supply of doctors, pharmacists, and PTs is likely to be surplus. The HRH requirements are likely to match with the supply in cases of dentists, MTs, and TTM practitioners.

Conclusion: In 2026, the supply of key professionals is likely to be sufficient except nurses who will be in critical shortages. The health demand method, although facing some limitations, is useful to project HRH requirements in such a situation that people are accessible to health services and future service utilizations are closely linked to current utilization rates.
\end{abstract}

Keywords: Human resources for health planning, Health demand method, Thailand

\section{Introduction}

Human resources for health (HRH) availability has improved in some countries. Still, shortages, skill-mix imbalances, maldistribution, barriers to inter-professional collaboration, rural turn over, and limited availability of health workforce data persist in many countries [1]. Recent efforts by the World Health Organization (WHO), the Global Health Workforce Alliance (GHWA), and

\footnotetext{
* Correspondence: nongpa@kku.ac.th

${ }^{1}$ Faculty of Public Health, Khonkaen University, 123 Mitraphap road, Muang, Khonkaen 40000, Thailand

Full list of author information is available at the end of the article
}

partner organizations to facilitate the development of a global HRH strategy for the period 2016-2030 reflect the growing recognition of the importance of HRH planning. They also highlighted that "countries should build planning capacity to develop or improve HRH policy and strategies that quantify health workforce needs, demands and supply under different future scenarios" [1].

Human resources for health (HRH) planning is the process in which an organization attempts to estimate the HRH supplies and requirements; determine the most appropriate balance among the skills, distribution, and number of health workers; and make a plan to redress 
HRH challenges [2]. Effective HRH planning thus needs evidence-based information to support, so as HRH requirement and $\mathrm{HRH}$ supply projection can contribute quantitatively for the resilience HRH plan. Planning for $\mathrm{HRH}$ thus has a central role in order to continue progressing towards the realization of the sustainable development goals (SDGs).

Ranges of HRH projection approaches were made available; population ratio, health need, health demand, and service target methods and each of these approaches have their advantages and limitations [3]. The simple projection of population ratio method, although require less data, does not take into account the effects of changes in health service utilization and HRH performance [4]. Health need method explores changes in population needs for health services base on changes of patterns of health problems [3]. Compare to other methods, it is considered a comprehensive approach for HRH projection [4]; however, drawbacks include challenges in defining needs in terms of coverage and quality, and the projection may generate unrealistic number of $\mathrm{HRH}$ requirements without adjusting to mal-distribution [5]. Health demand method draws on observed service utilization rate, applies to future population profile, and converts to HRH requirements. The approach is appropriate for such health system that the population is accessible to a suitable mix of services. However, the approach requires considerable sets of data and the projection trends to base on status quo situation [5]. The service target approach sets targets for specific services using current service provision, other factors, and expert opinions [4]. This approach may be useful in planning critical health care services or service for specific population; however, the approach may depend on unreliable assumptions [4]. Taking all these aspects into consideration, this study employed health demand method to forecast HRH requirement for Thailand health service system because of the high health service coverage of Thailand health service [6] and the availability of administrative data system.

\section{Thailand health service system}

Thailand is currently an upper middle-income country and is making progress towards meeting the SDGs. Although Thailand has made significant success in some health indicators (SDG 3), some other health challenges persist and need crucial attentions. The unfinished agenda of infectious diseases such as tuberculosis and HIV/AIDS coupling with non-communicable disease, such as cancer, cardiovascular diseases, diabetes mellitus, and hypertension, and traffic accident have threatened Thailand health system [7]. What is more, the increase of elderly health needs has prompted Thailand to improve health services to be in line with people needs.
With regard to the Thai health service system, virtually, everyone $(99.84 \%)$ was covered by health insurance while other forms of social security have expanded [8]. Available health facilities delivering services to people can be classified according to three-tier service systems: primary, secondary, and tertiary care facilities [9]. The primary health care facilities are the first contacts which individuals, families, and communities have with the health care system. Services provided incorporate common illness treatment, health promotion, disease prevention, rehabilitations, and community health interventions. This type of health facilities includes health centers and private clinics without bed. The secondary health care facilities provide curative care with the initial referral being made by the primary care professionals. Care provision is more complex and need higher medical expertise. Such health facilities include the Ministry of Public Health (MoPH) community hospitals, other public hospitals, and private hospitals. The tertiary health care facilities provide specialized care, usually on referral from primary or secondary medical care personnel, by specialists working in a facility that has personnel and facilities for special investigation and treatment. These facilities include MoPH general and regional hospitals, university hospitals, other public hospitals, and private hospitals [9].

Approximately $54 \%$ of Thai population resides in rural areas where they are mainly served by health facilities responsible to $\mathrm{MoPH}$ [10]. These include 9777 health centers which cover $100 \%$ of all sub-districts and 780 community hospitals (range from 30 to 120 bed hospitals) covering $88.8 \%$ of all districts [8]. The primary health care facilities located at urban areas comprise $\mathrm{MoPH}$ community medical centers, municipality health centers, private medical clinics, and drug stores. In urban areas of 77 provinces, the secondary and tertiary medical services are provided by $177 \mathrm{MoPH}$ hospitals, 11 medical school hospitals, 105 other public hospitals, and 249 private hospitals [8].

\section{HRH planning challenges}

The density of doctors, nurses, and midwives of Thailand was 3.1/1000 population [11], well below the recommendation threshold of 4.45/1000 population [1], indicating the shortages of HRH. In addition, the maldistribution of $\mathrm{HRH}$, particularly between rural and urban areas, hindered the progress of the Thai health system. It is well recognized that, to address the HRH challenges, the HRH requirements should be aligned with the health system needs in terms of the number, skills, and distribution. The evidence-based quantification of $\mathrm{HRH}$ requirements is thus required. Already several attempts have been made to estimate and forecast the $\mathrm{HRH}$ requirements for doctors [12], dentists [13], nurses [14], and pharmacists [15]; some challenges have been elucidated. The requirements 
were dated and each professional was projected individually without taking into account for team-based planning. Moreover, the requirements were mainly focused on public sectors which were likely to underestimate the country requirements. This study is therefore attempted to fill the gaps by forecasting HRH team in 2026 which comprise doctors, dentists, nurses, pharmacists, MTs, PTs, and TTM practitioners in primary health care, secondary health care, and tertiary health care services in Thailand.

\section{Methods}

To forecast the HRH requirements, the approach mainly relied on the secondary data and stakeholder committee opinions. Since the available secondary data were mostly related to curative and rehabilitative service utilization, the health demand method or service utilization method was then used to project HRH requirements. It is suggested that this method is appropriate for the countries where service utilization and related data are available and people are accessible to health services [5]. The method was considered appropriate as this study focused mainly on $\mathrm{HRH}$ requirements relating to service utilization at 3 health facility settings: primary, secondary, and tertiary health facilities. The high health insurance coverage (99.84\% of population) and low unmet health needs (1.5\% of sick patients) [6] have justified the utilization of the health demand method. HRH professionals included in the forecast are HRH whose main functions are related to curative and rehabilitative services including doctors, dentists, nurses, pharmacists, MTs, PTs, and TTM practitioners.

Health demand method forecasts the HRH requirements based on the forecasted service utilizations and then converts to $\mathrm{HRH}$ requirements by the staffing norm and productivity as the following steps.

1. Set up a technical working group (TWG) comprised of 13 members who have particular knowledge and expertise in service delivery. To ensure all concerned professionals involved, 7 representatives from 7 professional councils (medical, nursing, dentist, pharmacist, MT, PT, TTM practitioner councils), 2 representatives from primary care facilities, 2 representatives from secondary care facilities, and 2 representatives from tertiary care facilities were included into the TWG members. The TWG met regularly to provide technical input and expert opinions at each step of the projection process.

2. Identify main services provided by each professional at each particular level of care. Based on services provided by health facilities under $\mathrm{MoPH}$, researchers reviewed main services and presented to the TWG to discuss and approve main service to be included. At the primary care level, main services included were outpatient, dental, drug dispensing, and rehabilitation services. At the secondary and tertiary care level, main services consisted of services in relation to outpatient (OP), inpatient (IP), surgery, birth delivery, accident and emergency (A\&E), intensive care unit (ICU), ultra sound, drug dispensing, dental care, laboratory, and TTM services (Table 1). Outpatient services at the primary care, for instance, were provided by doctors, dentists, nurses, and TTM practitioners, while outpatient services at the secondary and tertiary care facilities were provided by doctors, dentists, nurses, pharmacists, MTs, PTs, and TTM practitioners.

Different service activities were provided differently by each professional, according to their professional roles and functions. The proportion of work allocations among health workforce team have been decided among TWG based on the expert experience. Due to unavailability of doctors at the rural primary care, doctors provided treatment services for about $20 \%$ of outpatients at public facilities, and $100 \%$ of outpatients services were provided by nurses. However, doctors provided services to all outpatient services at private clinics. At the secondary and tertiary health facilities, $100 \%$ of outpatient services are provided by both doctors and nurses. Pharmacists dispensed at about $20 \%$ of outpatients at primary care, and $70 \%$ of outpatient visits and inpatient days at secondary and tertiary care levels required drug dispensing service. All dental services at all 3 levels of care were provided by dentists. Due to unavailability of PTs and MTs at primary care, physiotherapy and laboratory services were only provided at secondary and tertiary care facilities. According to the Department of Thai Traditional Medicine [16], TTM service clients were estimated to $17.5 \%$ of general outpatients and 70\% of this figure needed Thai traditional interventions (see details in Table 1).

3. Collect the service utilizations and related data to project the service utilizations in the next 10 years (2026), and these steps were followed:

1) Collect and collate the MoPH administration data relating to service utilizations at 3 levels of care. Since the 2013 data provided details of annual volume of main services provided at each level of care and was verified by MoPH committee [17], the TWG decided to use the service utilization and related data produced in 2013 for the purpose of HRH projection.

2) $\mathrm{MoPH}$ service utilization proportion by age and sex was used to compare with the country population of the same age and sex in 2013 [18]. 
Table 1 Main services, work productivity, and proportion of work allocation by professionals and level of care

\begin{tabular}{|c|c|c|c|c|c|}
\hline \multirow[t]{2}{*}{ Professionals } & \multirow[t]{2}{*}{ Main services } & \multicolumn{2}{|l|}{ Primary care } & \multicolumn{2}{|c|}{ Secondary and tertiary care } \\
\hline & & $\begin{array}{l}\text { Proportion of } \\
\text { workload (\%) }\end{array}$ & $\begin{array}{l}\text { time/service } \\
\text { (hours) }\end{array}$ & $\begin{array}{l}\text { Proportion of workload } \\
(\%) / \text { number }\end{array}$ & $\begin{array}{l}\text { time/service } \\
\text { (hours) }\end{array}$ \\
\hline \multirow[t]{8}{*}{ Doctors } & OP Treatment & $20 \%$ & 0.12 & $100 \%$ & 0.12 \\
\hline & IP treatment & - & - & $100 \%$ & 0.33 \\
\hline & Surgery & - & - & $100 \%$ & $2.5^{\mathrm{a}}$ \\
\hline & Normal delivery & - & - & $100 \%$ & 0.25 \\
\hline & Abnormal delivery & - & - & $100 \%$ & 2.5 \\
\hline & A\&E services & - & - & $100 \%$ & 0.25 \\
\hline & ICU services & - & - & $100 \%$ & 1 \\
\hline & Ultrasound services & - & - & $100 \%$ & 0.25 \\
\hline \multirow[t]{8}{*}{ Nurses } & OP Treatment & $100 \%$ & 0.2 & $100 \%$ & 0.2 \\
\hline & IP treatment & - & - & $100 \%$ & 3.5 \\
\hline & Surgery & - & - & $100 \%$ & $4^{\mathrm{a}}$ \\
\hline & Normal delivery & - & - & $100 \%$ & $7^{a}$ \\
\hline & Abnormal delivery & - & - & $100 \%$ & $4^{a}$ \\
\hline & A\&E services & - & - & $100 \%$ & 0.6 \\
\hline & ICU services & - & - & $100 \%$ & 12 \\
\hline & Ultrasound services & - & - & $100 \%$ & 1 \\
\hline \multirow[t]{2}{*}{ Pharmacists } & OP Dispensing & $20 \%$ & 0.08 & $70 \%$ & 0.08 \\
\hline & IP Dispensing & - & - & $70 \%$ of patient days & 0.08 \\
\hline \multirow[t]{3}{*}{ Dentists } & General services & $100 \%$ & 0.47 & $100 \%$ & 0.47 \\
\hline & Special services & - & - & $100 \%$ & 2 \\
\hline & IP services & - & - & $100 \%$ & 3 \\
\hline Physiotherapists & PT services & $100 \%$ & 0.8 & $100 \%$ & 0.8 \\
\hline \multirow[t]{2}{*}{ Thai traditional practitioners } & Diagnosis & $17.5 \%$ of $\mathrm{OP}$ & 0.12 & $17.5 \%$ of $\mathrm{OP}$ & 0.12 \\
\hline & Thai traditional treatment & $70 \%$ of above & 1 & $70 \%$ of above & 1 \\
\hline \multirow[t]{7}{*}{ Medical Technicians } & Specimen collection & - & - & $100 \%$ & 0.02 \\
\hline & Hematology services & - & - & $100 \%$ & 0.15 \\
\hline & Microscope services & - & - & $100 \%$ & 0.17 \\
\hline & Clinical chemistry services & - & - & $100 \%$ & 0.03 \\
\hline & Immunology services & - & - & $100 \%$ & 0.1 \\
\hline & Microbiology services & - & - & $100 \%$ & 0.33 \\
\hline & Molecular biology and blood services & - & - & $100 \%$ & 0.18 \\
\hline
\end{tabular}

${ }^{a}$ Operation carried out at secondary and tertiary services require 1.5 doctors and 2.5 nurses per case. Normal delivery requires 2 nurses and abnormal delivery require 2.5 nurses for each case

The derived proportion was then used to multiply the projected population in 2026 of the same age and sex in order to obtain the projected service utilization at each level of care in 2026. By this approach, it was under the assumption that the pattern of service utilizations would remain constant in the future.

3) Use the percentage of service utilization by health facility types $(\mathrm{MoPH}$, other public and private facilities) obtained from the survey report of the National Statistical Office [6] to add on the volume of the MoPH service utilization. Of all outpatient visits, 70, 24, and $6 \%$ of them used the services at $\mathrm{MoPH}$ facilities, private facilities, and other public facilities, respectively. For in-patient utilization, 76, 16, and $8 \%$ of all inpatients used the services at $\mathrm{MoPH}$ facilities, private facilities, and other public facilities, respectively. Regarding dental services, the unmet need was $1.05 \%$, and service 
utilization at private and other public sectors were $41.44 \%$ and $4.41 \%$, respectively. To obtain overall service utilization of the country, the service utilization of other public facilities and private facilities is added on to those of the MoPH's. In addition, to ensure the unmet needs have been covered, the unmet needs of $1.5 \%$ of outpatients and $0.14 \%$ of inpatients [6] were topped up.

4. Identify work productivity and workload of each professional at each level of care. Time requirement per service of each professional was obtained from the MoPH information system [17] and presented to TWG for the consensus of expert opinions. Service hour per case of doctors were 0.12, 0.25, 0.25 , and $2.5 \mathrm{~h}$ for outpatient, A\&E, ultrasound, and surgery services, respectively. Nursing time services for outpatient, A\&E, ultrasound, and surgery services were $0.2,0.6,1$, and $4 \mathrm{~h} /$ case, respectively. As IP and ICU patients needed 24-h services, doctors spent $0.33 \mathrm{~h}$ and $1 \mathrm{~h}$ per patient day and nurses spent $3.5 \mathrm{~h}$ and $12 \mathrm{~h}$ per patient day, respectively. Surgery service carried out at secondary and tertiary facilities required a team of 1 and a half doctors and 2 and a half nurses per case. Normal delivery service required 2 nurses and abnormal delivery service required 2 and a half nurses for each case. Pharmacy service included was limited only to drug dispensing service and took $0.08 \mathrm{~h}$ per prescription. Dental service time requirement ranged from 0.47 to $3 \mathrm{~h}$ per service. PT spent $0.8 \mathrm{~h}$ for a case. TTM practitioner took 0.12 and $1 \mathrm{~h}$ per case for diagnosis and Thai traditional intervention, respectively. Ranges of laboratory services carried out by MTs took about $0.02-0.33 \mathrm{~h}$ per test (see more details in Table 1).

5. Calculate workload by multiplying the number of annual services of the year 2013 by the time spent per service by each professional at each level of care. Doctor, for instance, carried out 110290828 outpatient services at secondary care and doctor workloads were calculated equal to 13234899 man hours $(110290828 \times 0.12 \mathrm{~h})$. The calculation at each level of care in the year 2013 and 2026 were carried out using the same approach.

6. Convert workload into HRH requirements. The TWG used the staff norm set by the MoPH [17] in which 1 full-time equivalent (FTE) equaled 1680 working hours per year (working $7 \mathrm{~h}$ a day and 240 days a year) to convert workload into HRH requirements. Doctor requirements for outpatient service, for instance, were obtained from dividing doctor outpatient workload, 13234899 man hours by 1 FTE (1680 working hours per year); the number of doctor requirements for outpatient service was thus 7878 FTE doctors.

7. Determine the time spent for other services/ activities. Although workload included in this study was mainly curative and rehabilitation services, $\mathrm{HRH}$ daily functions should include other important aspects, such as home health care services, health promotion services, disease prevention and public health interventions, administrative work, meeting, leave, and capacity building. Therefore, based on the time motion study of Pagaiya et al. [19], the TWG reviewed and decided the allowance level to accommodate other necessity activities of $\mathrm{HRH}$. At secondary and tertiary care, the allowance across all professionals, except pharmacists, were 15\% of their FTE. Since pharmacist's main activities consist of drug dispensing, drug/medical supply production, and drug and medical supply management, the proportion of their time spent for drug dispensing was approximated at about $56 \%$. The pharmacist allowance was therefore agreed at $44 \%$. At primary care, nurses, dentists, pharmacists, and TTM practitioners have to carry out outreach activities at the community and some other administrative works; the allowance proportion allocated for other work was agreed at $30 \%$.

After converting workloads into the HRH requirements, the allowance proportion was toped up at each professional. Doctor requirements at primary care was $7275 \mathrm{FTE}$; for instance, the requirements after addition of $15 \%$ allowance was 8366 FTE.

In the projected scenario in 2026, it was presumed that all planning variables except population are held constant at current levels.

8. Match the projected $\mathrm{HRH}$ requirements with the projected HRH supply. The supply projections were reviewed from the 7 professional requirement and supply studies [20-26]. The stock and flow model was used for each study in order to project the HRH supply in 2026 [11]. The current stock of each professional was obtained from the licensed $\mathrm{HRH}$ who were actively practicing. The potential inflow into the HRH stock was based on the production plan of each professional, while the outflow against the stock was defined according to the potential number of retirements, death, resignation from the health system, and drop out from colleges/ universities. As the emigration and immigration of HRH was minimal, so this information was not taken into account for the forecast. The projected HRH supply was then calculated and matched with the projected requirements to identify the HRH imbalance. 


\section{Results}

\section{HRH requirements in 2013}

At primary care, only outpatient services were included in the HRH workload. The total outpatient services were 210876061 visits. Of this figure, 74587669 visits took place at private facilities in 2013. Doctor outpatient services were 27257679 visits at public facilities and 74 587669 visits at private facilities. The workload calculation was equal to 12221441 working hour and that made 7275 doctor requirements. Nurses provided services to all 210587669 visits, and the conversion of nursing workload resulted in 25104 nurse requirements. Drug dispensing provided by pharmacists for 42175212 visits was converted to 2092 pharmacist requirements. Dentists delivered 10170917 general dental services, and 2825 dentists were required for providing such dental care services at primary care facilities. The TTM services provided at primary health care facilities was 29 438293 services, and that required 4673 TTM practitioners. When $30 \%$ allowance for outreach and other activities at primary health care facilities were added up for all professionals, excepted doctor which only $15 \%$ of allowance was topped up, the requirements for doctors, nurses, pharmacists, dentists, and TTM practitioners are shown in Table 2.

The services provided and HRH requirements at secondary and tertiary care facilities are shown in Tables 3 and 4 . The quantity of services provided by doctors and nurses at secondary care were dominated by OP services, IP services, A\&E services, ultrasound services, and normal and abnormal delivery services at approximately 110290828 visits, 12949845 patient days, 5974225 visits, 902553 visits, and 281048 cases and 15664 cases, respectively. Comparing to those of the secondary care, although OP services at tertiary care facilities were about a half, the IP services was double, particularly those of the ICU service which were about 19 times more. The number of surgical cases was almost 13 times higher, and the abnormal delivery cases were about 3 times higher. All other services were comparable. Drug

Table 2 Workload and HRH requirements at primary health care services in 2013

\begin{tabular}{lllll}
\hline Professionals & $\begin{array}{l}\text { No. of } \\
\text { services }\end{array}$ & $\begin{array}{l}\text { Man } \\
\text { hours }\end{array}$ & \multicolumn{2}{l}{ HRH requirements (FTE) } \\
\cline { 5 - 6 } & & & & \\
Doctors & & Include allowance \\
Public facilities & 27257679 & 3270921 & 1947 & 8366 \\
$\quad$ Private facilities & 74587669 & 8950520 & 5328 & \\
Nurses & 210876061 & 42175212 & 25104 & 32635 \\
Pharmacists & 42175212 & 3514601 & 2092 & 2720 \\
Dentists & 10170917 & 4746428 & 2825 & 3249 \\
TTM Practitioners & 29438293 & 7850211 & 4673 & 6075 \\
\hline
\end{tabular}

dispensing at tertiary care was slightly higher than those at secondary care. Laboratory services provided were about 3 times as high as those at secondary care. Clinical chemistry, microbiology, molecular biology, and blood banking tests/services were greatly higher at tertiary care. Details are shown in Table 3.

Dental services, PT services, and TTM services were higher at secondary care facilities, compared to those at tertiary care facilities. Dental services at secondary care services were 3 times as high as those of tertiary care services and the PT services at secondary care were slightly higher than those at tertiary care facilities. TTM services provided at secondary care facilities were about 1.8 times higher than those at the tertiary care. Details are shown in Table 4.

When working hour was conversed into HRH requirements and topped up with allowance percentage (44\% for pharmacists and $15 \%$ for all other professionals), the secondary care health system required 13596 doctors, 53753 nurses, 6995 pharmacists, 5339 MTs, 7651 dentists, 2040 PTs, and 8262 TTM practitioners. The HRH requirements for tertiary care were 15, 576 doctors, 106 680 nurses, 5926 pharmacists, 7546 MTs, 3471 dentists, 1920 PTs, and 4660 TTM practitioners.

\section{$\mathrm{HRH}$ requirements in 2026}

The projection of service utilization and HRH requirements in 2026 are shown in Tables 5 and 6. The amount of OP services in 2016 will be the highest at the primary care compared to the secondary and the tertiary care. IP services are highest at the tertiary care; particularly, ICU services will be approximately 19 times of those of the secondary care. Surgery, abnormal delivery and ultrasound services will be also performed highest at the tertiary care. In contrast, A\&E services will be higher at the secondary care facilities. Accordingly, laboratory services will be higher at the tertiary care. The volume of drug dispensing at the secondary care will be higher compared to that at the tertiary or the primary care. Details are given in Table 5 .

Dental services will be highest at the secondary care compared to the primary or tertiary care. PT services at the secondary care will be close to those at the tertiary care. TTM services will be high at the primary and the secondary care compared to the tertiary care. Details are given in Table 6.

The projection of HRH requirement in 2026, after inclusion of allowance percentage, revealed that the health service system at the primary care facilities will require 8535 doctors, 29691 nurses, 3118 pharmacists, 3575 dentists, and 6534 TTM practitioners. The secondary health facilities will require 14998 doctors, 59489 nurses, 7713 pharmacists, 5901 MT, 8416 dentists, 2254 PTs, and 9096 TTM practitioners. The projected tertiary 
Table 3 Workload and requirements of doctors, nurses, pharmacist, and MT by level of care in 2013

\begin{tabular}{|c|c|c|c|c|c|c|}
\hline \multirow[t]{2}{*}{ Professionals/services } & \multicolumn{3}{|c|}{ Secondary care } & \multicolumn{3}{|l|}{ Tertiary care } \\
\hline & $\begin{array}{l}\text { No. of } \\
\text { services }\end{array}$ & Man hours & $\begin{array}{l}\text { HRH requirements } \\
\text { (FTE) }\end{array}$ & $\begin{array}{l}\text { No. of } \\
\text { services }\end{array}$ & Man hours & $\begin{array}{l}\text { HRH requirements } \\
\text { (FTE) }\end{array}$ \\
\hline \multicolumn{7}{|l|}{ Doctors } \\
\hline OP treatment & 110290828 & 13234899 & 7878 & 62206113 & 7464734 & 4443 \\
\hline IP treatment & 12949845 & 4273449 & 2544 & 21046774 & 6945435 & 4134 \\
\hline Surgery & 106549 & 399557 & 238 & 1352510 & 4463283 & 2657 \\
\hline Normal delivery & 281048 & 70262 & 42 & 243857 & 60964 & 36 \\
\hline Abnormal delivery & 15664 & 39160 & 23 & 43368 & 95409 & 57 \\
\hline A\&E services & 5974225 & 1493556 & 889 & 4851152 & 1212788 & 722 \\
\hline ICU & 125683 & 125683 & 75 & 2386955 & 2386955 & 1421 \\
\hline Ultrasound services & 902553 & 225638 & 134 & 970912 & 242728 & 144 \\
\hline Total (include 15\% allowance) & & & 13596 & & & 15657 \\
\hline \multicolumn{7}{|l|}{ Nurses } \\
\hline OP Treatment & 110290828 & 22058166 & 13061 & 62206113 & $12,441,2239$ & 7405 \\
\hline IP treatment & 12949845 & 45324456 & 37187 & 21046774 & 94710483 & 56375 \\
\hline Surgery & 106549 & 1065487 & 874 & 1352510 & 12781220 & 7608 \\
\hline Normal delivery & 281048 & 3934676 & 3228 & 243857 & 3414004 & 2032 \\
\hline Abnormal delivery & 15664 & 156639 & 129 & 43368 & 409824 & 244 \\
\hline A\&E services & 5974225 & 3584535 & 2122 & 4851152 & 2522599 & 1502 \\
\hline ICU & 125683 & 1508195 & 1237 & 2386955 & $28,643,4579$ & 17050 \\
\hline Ultrasound services & 902553 & 902553 & 741 & 922366 & 922366 & 549 \\
\hline Total (include 15\% allowance) & & & 53759 & & & 106680 \\
\hline \multicolumn{7}{|l|}{ Pharmacists } \\
\hline Drug dispensing & 68346611 & 5695551 & 4857 & 82958564 & 6913214 & 4115 \\
\hline Total (include 44\% allowance) & & & 6995 & & & 5926 \\
\hline \multicolumn{7}{|l|}{ MT } \\
\hline Specimen collection & 16076429 & 267940 & 159 & 10058590 & 167643 & 100 \\
\hline Hematology & 15897187 & 2384578 & 1419 & $18,391,769$ & $2,758,765$ & 1642 \\
\hline Microscope & 9857133 & 1642855 & 978 & 7,898760 & 1316,460 & 784 \\
\hline Clinical chemistry & 76216024 & 1905401 & 1134 & 101608462 & 2540212 & 1,512 \\
\hline Immunology & 6526278 & 652628 & 388 & 8350144 & 835014 & 497 \\
\hline Microbiology & 2377038 & 792346 & 472 & 6433612 & 2144537 & 1277 \\
\hline Molecular biology and blood banking & 842625 & 154037 & 92 & 6893524 & 1259161 & 750 \\
\hline Total (include 15\% allowance) & & & 5339 & & & 7546 \\
\hline
\end{tabular}

care services will require 17342 doctors, 118488 nurses, 6555 pharmacists, 8348 MT, 4569 dentists, 2124 PTs, and 5131 TTM practitioners.

\section{Sensitivity analysis}

The effective HRH requirements is dependent not only on the number of service utilization but also on the average time spent on each service, working hour, proportion of time spent on other activities, etc. Time spent on each service or productivity of each professional varies across health facilities including public and private sectors or even within health facilities. The range of time spent on each service, i.e., the baseline time and the baseline time $\pm 10 \%$, were chosen to perform sensitivity of various scenarios, while other factors held constant. Table 8 demonstrates the sensitivity of $\mathrm{HRH}$ requirements to different level of time spent per service. The higher the time spent per service, the higher the number of HRH requirements. 
Table 4 Workload and requirements of dentists, PT and TTM practitioners by level of care in 2013

\begin{tabular}{|c|c|c|c|c|c|c|}
\hline \multirow{2}{*}{$\begin{array}{l}\text { Professionals/ } \\
\text { services }\end{array}$} & \multicolumn{3}{|l|}{ Secondary care } & \multicolumn{3}{|l|}{ Tertiary care } \\
\hline & No. of services & Man hours & HRH requirements (FTE) & No. of services & Man hours & HRH requirements (FTE) \\
\hline \multicolumn{7}{|l|}{ Dentists } \\
\hline General & 16695081 & 7791038 & 4638 & 5442507 & 2539836 & 1512 \\
\hline Special & 1679730 & 3359460 & 2000 & 1244250 & 2488500 & 1481 \\
\hline IP services & 8981 & 26944 & 16 & 14279 & 42837 & 25 \\
\hline \multicolumn{3}{|c|}{ Total (include 15\% allowance) } & 7651 & & & 3471 \\
\hline \multicolumn{7}{|l|}{ Physiotherapists } \\
\hline PT services & 4244360 & 2979466 & 1773 & 3801182 & 2805212 & 1670 \\
\hline \multicolumn{3}{|c|}{ Total (include 15\% allowance) } & 2040 & & & 1920 \\
\hline \multicolumn{7}{|l|}{ TTM practitioners } \\
\hline Diagnose & 19311924 & 4827981 & 2874 & 10892290 & 2723073 & 1621 \\
\hline TTM interventions & 9655962 & 7241971 & 4311 & 5446145 & 4084609 & 2431 \\
\hline \multicolumn{3}{|c|}{ Total (include 15\% allowance) } & 8262 & & & 4660 \\
\hline
\end{tabular}

Table 5 Workload and requirements of doctors, nurses, pharmacist, and MT by level of care in 2026

\begin{tabular}{|c|c|c|c|c|c|c|}
\hline \multirow[t]{2}{*}{ Professionals/services } & \multicolumn{2}{|l|}{ Primary care } & \multicolumn{2}{|l|}{ Secondary care } & \multicolumn{2}{|l|}{ Tertiary care } \\
\hline & No. of services & HRH requirements (FTE) & No. of services & HRH requirements (FTE) & No. of services & $\mathrm{HRH}$ requirements (FTE) \\
\hline \multicolumn{7}{|l|}{ Doctors } \\
\hline OP Treatment & 103902454 & 7422 & 121424710 & 8673 & 68490610 & 4892 \\
\hline IP treatment & & & 14366573 & 2822 & 23399074 & 4596 \\
\hline Surgery & & & 118205 & 264 & 1503674 & 2954 \\
\hline Normal delivery & & & 311795 & 46 & 271112 & 40 \\
\hline Abnormal delivery & & & 17378 & 26 & 48215 & 63 \\
\hline A\&E services & & & 6577325 & 979 & 5341249 & 795 \\
\hline ICU care & & & 139433 & 83 & 2653734 & 1580 \\
\hline Ultrasound services & & & 997480 & 148 & 1074213 & 160 \\
\hline Total (include allowance & & 8535 & & 14998 & & 17342 \\
\hline \multicolumn{7}{|l|}{ Nurses } \\
\hline OP Treatment & 221161598 & 22839 & 121,424710 & 14455 & 68490610 & 8154 \\
\hline IP treatment & & & 14366573 & 29930 & 23399074 & 62676 \\
\hline Surgery & & & 118205 & 704 & 1503674 & 8458 \\
\hline Normal delivery & & & 311795 & 2598 & 271112 & 2259 \\
\hline Abnormal delivery & & & 17378 & 103 & 48215 & 271 \\
\hline A\&E services & & & 6577325 & 2349 & 5341249 & 1653 \\
\hline ICU care & & & 139433 & 996 & 2653734 & 18955 \\
\hline Ultrasound services & & & 997480 & 594 & 1074213 & 607 \\
\hline Total (include allowance & & 29691 & & 59489 & & 118488 \\
\hline \multicolumn{7}{|l|}{ Pharmacists } \\
\hline Drug dispensing & 44232320 & 2165 & 107983815 & 5356 & 91762863 & 4552 \\
\hline \multicolumn{2}{|l|}{ Total (include allowance) } & 3118 & & 7713 & & 6555 \\
\hline MT & - & - & & & & \\
\hline Med Lab. services & & & 141233405 & 5131 & 176619399 & 7259 \\
\hline \multicolumn{3}{|l|}{ Total (include allowance) } & & 5901 & & 8348 \\
\hline
\end{tabular}


Table 6 Workload and requirements of dentists, PT, TTM practitioners by level of care in 2026

\begin{tabular}{|c|c|c|c|c|c|c|}
\hline \multirow{2}{*}{$\begin{array}{l}\text { Professionals/ } \\
\text { services }\end{array}$} & \multicolumn{2}{|l|}{ Primary care } & \multicolumn{2}{|l|}{ Secondary care } & \multicolumn{2}{|l|}{ Tertiary care } \\
\hline & No. of services & HRH requirements (FTE) & No. of services & HRH requirements (FTE) & No. of services & HRH requirements (FTE) \\
\hline \multicolumn{7}{|l|}{ Dentists } \\
\hline Dental services & 11188009 & 3108 & 20222171 & 7319 & 8588238 & 3973 \\
\hline \multicolumn{2}{|c|}{ Total (include allowance) } & 3574 & & 8416 & & 4569 \\
\hline Physiotherapists & - & - & & & & \\
\hline PT services & & & 4690764 & 1960 & 4205613 & 1847 \\
\hline \multicolumn{3}{|c|}{ Total (include allowance) } & & 2254 & & 2124 \\
\hline \multicolumn{7}{|l|}{ TTM practitioners } \\
\hline TTM services & 31659908 & 5026 & 31892200 & 7910 & 17989059 & 4462 \\
\hline \multicolumn{2}{|c|}{ Total (include allowance) } & 6534 & & 9096 & & 5131 \\
\hline
\end{tabular}

\section{HRH supply projection in 2026}

The HRH supply projection was derived from the professional studies of doctors [20], nurses [21], dentists [22], pharmacists [23], MTs [24], PTs [25], and TTM practitioners [26], for which the stock and flow method was used. The number of doctors existing in 2013 was 41746 , and the ratio per 1000 population was 0.65 . The flow in data derived from the newly graduates of all medical schools were 3121 annually. The doctor flow out was approximately $1 \%$ loss rate from death and retirement and approximately $25 \%$ of registered doctors do not engage in clinical practice. The doctor supply in 2026 is projected to 62779 doctors. The existing nurses in 2013 were 158 317, and the newly entrants of nursing students are about 10000 nurses per year. Flow out was calculated from $4.44 \%$ loss rate due to change of jobs, retirements and deaths, and 5\% drop out rate of nursing students. The projection of nurses in 2026 is estimated to 180992 nurses.

Pharmacist stock was 24940 in 2013, and the production plan is approximately 1700 pharmacists per year. Taking into account of $2 \%$ loss rate per year, the pharmacist projection is amounted to 38905 in 2026. Current dentist stock was 10506 in 2013. With 825 dentist production per year and $1.5 \%$ loss rate, the projection of dentists is estimated to be 18675 in 2026.

The number of PTs existing in 2013 was 4301, and the annual student entrants are 1155 per year. Loss rate of PTs comprised of $2 \%$ from death and retirement, $20 \%$ of dropout rate of PT students, and $5 \%$ of those not engage in PT services. Taking into account flow in and flow out rates, the PT projection in 2026 is estimated to be 9736 . The number of TTM practitioners existing in 2013 was 9224. With 1080 TTM practitioner graduates per year and $2 \%$ loss rate from death and retirement, the projection of TTM practitioners in 2026 is 19080 . In 2013, the existing MTs were 14047 . The newly graduates of MTs per year are 911 and the loss rate is $5 \%$ per year. The MT projection in 2026 is estimated to be 16078 . See details in Table 7.

\section{Matching HRH requirements and supplies in 2026}

Table 8 illustrates the comparison between HRH requirements and supplies, and the gap identification in

Table 7 Current and projected HRH supply by professional

\begin{tabular}{|c|c|c|c|c|c|}
\hline \multirow[t]{2}{*}{ Professionals } & \multicolumn{2}{|c|}{ Current HRH (2013) } & \multirow{2}{*}{$\begin{array}{l}\text { Production/ } \\
\text { year }\end{array}$} & \multirow[t]{2}{*}{ Loss rate/year } & \multirow{2}{*}{$\begin{array}{l}\text { Projected supply } \\
\text { (2026) }\end{array}$} \\
\hline & number & Population ratio(/1 000) & & & \\
\hline Doctors & 41746 & 0.65 & 3121 & $\begin{array}{l}-3 \% \text { drop out from medical students } \\
-1 \% \text { loss from death and retirement } \\
-25 \% \text { of registered doctors not involve in clinical practice }\end{array}$ & 62779 \\
\hline Nurses & 158317 & 2.45 & 10000 & $\begin{array}{l}-5 \% \text { drop-out rate of nursing students } \\
-4.44 \% \text { loss from change job, death and retirement }\end{array}$ & 180992 \\
\hline Pharmacists & 24940 & 0.38 & 1700 & $2 \%$ loss from death and retirement & 38905 \\
\hline Dentists & 10506 & 0.16 & 826 & $1.5 \%$ loss from death and retirement & 18675 \\
\hline PT & 4301 & 0.07 & 1155 & $\begin{array}{l}-20 \% \text { drop out rate of PT students } \\
-2 \% \text { loss from death and retirement } \\
-5 \% \text { not involve in PT services }\end{array}$ & 9736 \\
\hline TTM practitioners & 9224 & 0.14 & 1080 & $2 \%$ loss from death and retirement & 19080 \\
\hline MT & 14047 & 0.22 & 911 & $5 \%$ loss from death and retirement & 16078 \\
\hline
\end{tabular}


Table 8 HRH requirements VS supply in 2016

\begin{tabular}{lllll}
\hline & HRH requirements in 2026 & & $\begin{array}{l}\text { HRH supply } \\
\text { in 2026 }\end{array}$ & Shortages/surplus \\
\cline { 2 - 5 } & Baseline time & Baseline time $\pm 10 \%$ & 62779 & 17818 to 25993 \\
\hline Doctors & 40875 & $36786-44961$ & 180992 & -5909 to -47443 \\
Nurses & 207668 & $186901-228435$ & 38905 & 19780 to 23258 \\
Pharmacists & 17386 & $15647-19125$ & 18675 & 461 to 3772 \\
Dentists & 16559 & $14904-18215$ & 9736 & 4920 to 5796 \\
Physiotherapists & 4378 & $3940-4816$ & 19080 & $-3,757$ to 395 \\
TTM practitioners & 20761 & $18685-22837$ & 16078 & 404 to 3254 \\
MT & 14249 & $12824-15674$ & &
\end{tabular}

2026. Nurses are likely to be in critical shortages, since there is a requirement of about 186901-228 435 nurses, but the number of nurses supplied is projected to be 180 992. Some professionals', for instance, doctors, pharmacists, and PTs, supply are likely to be surplus at about 17 818-25 993 doctors, 19780-23 258 pharmacists, and 4920-5796 PTs. In cases of dentists, MTs, and TTM practitioners, the $\mathrm{HRH}$ requirements are likely to match with the HRH supply.

\section{Discussion}

Although various approaches have been carried out to increase the accuracy in projecting the future HRH requirements and supplies, this kind of study often faces some limitations. First, several factors critically affecting demand of health care are not taken into account in the projection. Challenges facing Thai health system including rapid increase of aging population, increase of people living with chronic conditions, and growing demand of services provided in home and community settings should be included in the projection to show the direction towards which the health service system and HRH situation may be heading. Second, service utilization data used were focused mainly on curative and rehabilitation services. Health services in relation to health promotion, disease prevention, and home health care were not taken into account. Third, the HRH requirements did not cover $\mathrm{HRH}$ working as administrators, lecturers, researchers, and business related to health. The projected HRH requirements in the study therefore were likely to be underestimated. Fourth, the study mainly used the secondary data from various sources in projecting HRH requirements and supplies. Since the quality of data was varied among the sources, the results have some risks in the data accuracy and integrity. Fifth, the $\mathrm{HRH}$ requirements varied upon the volume of service utilization, time spent on each service, working hour, and proportion of time spent on other activities. The fact that the changes of these figures critically affect the number of HRH requirement, the results should be viewed with considerations. Sixth, the TWG play important role on crucial figures affecting HRH requirements. Despite the fact that several key stakeholders involved in decision making, the results risk towards professional bias and likely to require more $\mathrm{HRH}$ than the health system can afford.

Despite some limitations, the present results demonstrated the potentials to project HRH requirements in a multi-professional manner rather than the single professional projection to consider the possible interaction and team work, particularly task sharing of doctors and nurses at the primary care level. The results support the recommendation made by Ono et al. [27] in that the $\mathrm{HRH}$ projection should shift from uni-professional to multi-professional approach. Moreover, in this study, multi-professional committees were involved at all important process of the HRH projection. This multi-professional projection approach has been carried out also in other studies, i.e., the calculation of family doctors, nurses, public health workers, and others at community health centers in China [28]; the projections of doctor, nurse, and midwife requirements in OEDC [29]; and the projection of skill-mix among doctors, advanced practice nurses, and physician assistants in Finland, the Netherland, Switzerland, and the United States of America [27].

The present results illustrated that, in 2026, doctors, pharmacists, and PTs were likely to be surplus, if the service system and HRH system be carried out as usual. On the other hand, the number of nurses will be in extremely shortage. The supply and requirements of dentists, MT, and TTM practitioners will be in balance. Comparing with the threshold of 4.45 (doctors + nurses + midwives) $/ 1000$ population to achieve the median score $(25 \%)$ of attainment of $80 \%$ coverage for the 12 selected SDG tracer conditions [1], the requirement of doctors and nurses in this study was about $3.64 / 1000$ population, slightly below the recommendation.

However, the HRH requirements in this study were likely to be underestimated. First, doctors and pharmacists provided care at about $20 \%$ of outpatient visits at public primary care facilities, and thus, the requirements 
of doctors and pharmacists were lower than what should be. Second, home health care for aged and chronically ill patients were not included in the scenario, so that the requirement of home health care providers, i.e., PTs, doctors, and nurses, were thus underestimated. Third, if drug industries and other drug-related functions were included in the projection, the requirements of pharmacists would be much higher. HRH requirements applying the service utilization for multi-professional approach in this study were lower than those used in different methods for single professional projections in Thailand. Dentist requirements in 2026 by the service target method by Jaichuen [18] showed the needs with the range of 19677-20 955 which were higher than the supply. Pharmacist projection by the system dynamic approach required 47787 pharmacists in 2026 [19]. Sawaengdee [17] combined service utilization and health need methods to project the nurse requirement which showed similar results to this study. At the same time, PT requirement by the combination of service utilization and service target approaches showed the requirements of 7855-8378 [21] which was higher than that of the results of this study.

Although the results of this study indicated that the production of key professional is likely to be sufficient, the concerned issues are the absorption, distribution, and retention of HRH which were not under the scope of this study.

There are some advantages of the use of health demand methods in projecting HRH requirements. This approach is appropriate for the countries where the population is accessible to a suitable mix of health services and future service utilization rates are closely linked to current utilization rates. The approach used in this study has already been used in several studies to project HRH future requirements, particularly for curative services. The health demand method was used to project for future doctor requirements in Mexico [30], Australia, Belgium, and Canada [27] and dentist requirements in Australia [31]. Moreover, the approach has been used at sub-national level, for example, there was an attempt to calculate the requirements for doctors, nurses, public health workers, and allied health workers working at community health center in a district in Beijing, China [28].

\section{Conclusion}

The results of this study implied that the production of key professional is likely to be sufficient in the future, except nurses which are likely to be in critical shortages. Health demand method used to project $\mathrm{HRH}$ requirements in this study, though there are some limitations, was likely to be applicable for countries where health service utilization constantly changed and was useful for micro-planning at the facility level. However, HRH planning should be reviewed and updated often as the context affecting health service is dynamic.

\begin{abstract}
Abbreviations
A\&E: Accident and emergency; FTE: Full-time equivalent; HRH: Human resources for health; ICU: Intensive care unit; IP: Inpatient; MoPH: Ministry of Public Health; MT: Medical technician; OP: Outpatient; PT: Physiotherapist; SDGs: Sustainable development goals; TTM: Thai traditional medicine
\end{abstract}

\section{Acknowledgements}

The authors acknowledge the financial support received from the National Health Systems Research Institute. We also thank Dr. Weeraphant Suphanachaimart and the technical working group members for providing valuable information, support, and recommendations.

\section{Funding}

The research received funding from the Health Systems Research Institute, Thailand.

\section{Availability of data and materials}

The data sets used and/or analyzed during the current study are available from the corresponding author on reasonable request.

\section{Authors' contributions}

$N P, P P, A B, T N$, and KK worked on the conception and detailed design of the study. NP, PT, AB, and KK collected and analyzed the data. All authors read and approved the manuscript.

Ethics approval and consent to participate

Not applicable as secondary data was used in the study.

Consent for publication

Not applicable.

\section{Competing interests}

The authors declare that they have no competing interests.

\section{Publisher's Note}

Springer Nature remains neutral with regard to jurisdictional claims in published maps and institutional affiliations.

\section{Author details}

${ }^{1}$ Faculty of Public Health, Khonkaen University, 123 Mitraphap road, Muang, Khonkaen 40000, Thailand. ${ }^{2}$ Naresuan University, Muang, Phitsanulok 65000, Thailand. ${ }^{3}$ Khon Kaen Provincial Health Office, Muang, Khonkaen 40000, Thailand. ${ }^{4}$ International Health Policy Program, Ministry of Public Health, Tiwanon road, Muang, Nonthaburi 11000, Thailand.

Received: 14 July 2018 Accepted: 3 December 2018

Published online: 08 January 2019

\section{References}

1. World Health Organization. Global strategy on human resources for health: workforce 2030. Geneva: WHO; 2015. p. 25.

2. Mejia A. The health manpower planning process. In: Hall TL, Mejia A, editors Health manpower planning: principles, methods, issues. Geneva: WHO; 1978. p. 31-56.

3. World Health Organization. Models and tools for health planning and projections. (human resources observer, 3). Geneva: WHO; 2010.

4. Hall TL. Demand and supply. In: Hall TL, Mejia A, editors. Health manpower planning: principles, methods, issues. Geneva: WHO; 1978. p. 57-116.

5. McQuide P, Stevens J, Settle D. An overview of human resources for health $(\mathrm{HRH})$ projection models: Technical brief 12. Chapel Hill: The Capacity Project; 2008. 
6. Ministry of Information and Communication Technology- National Statistical Office. The 2013 survey on health and welfare. Bangkok: National Statistical Office; 2014.

7. Bertelsmann Stiftung and Sustainable Development Solutions Network. SDG index and dashboards report 2017: global responsibilities, international spillovers in achieving the goals. 2017. http://www.sdgindex.org. Accessed 2 Feb 2017.

8. Ministry of Public Health (MoPH). Thailand health profiles 2011-2015 Nonthaburi: Ministry of Public Health; 2015.

9. Ministry of Public Health (MoPH)- Health Administration Division. Health service system development plan. Nonthaburi: Ministry of Public Health; 2012.

10. Pagaiya N, Tangcharoensathien V, Noree T, Sriratana S, Chantanis A. How to attract new doctors to work in rural areas: using discrete choice experiment (DCE). J Health Syst Res. 2012;6(1):40-7.

11. Noree T, editor. Policy options for the human resources for health planning in the next decade. Nonthaburi: Human Resources for Health Research and Development Office (HRDO); 2017.

12. Sirikanokwilai N, Wibulpolprasert S, Pengpaiboon P. Modified population-to physician ratio method to project future physician requirement in Thailand. Hum Resour Health Dev J. 1998;2(3):197-209.

13. Panyasingh $\mathrm{K}$, Udompanich $\mathrm{S}$, Lexomboon D. Baseline projection of requirements for dental health manpower in Thailand. Hum Resour Health Dev J. 1997:1(1):24-34.

14. Srisuphan W, Senaratana W, Kunaviktikul W, Tonmukuyakul O, Charoenyuth C, Sirikanokwilai N. Supply and requirement projection of professional nurses in thailand over the next two decade (1995-2015). Hum Resour Health Dev J. 1998;2(3):210-20.

15. Payanantana N, Sakolchai S, Pitaknitinun K, Palakornkul D, Thongnopnua N. (1998). Future human resources balance for pharmacy and health consumer protection services in Thailand. Hum Resour Health Dev J. 1998;2(2):129-41.

16. MoPH-Department of Thai Traditional and Alternative Medicine. Service utilization data system. Nonthaburi: MoPH; 2013.

17. MoPH - Working group for human resources for health planning. Service utilization at primary care, secondary care and tertiary care facilities under MoPH. Nonthaburi: MoPH; 2015.

18. Office of National Economics and Social Development Board (NESDB). Thailand population projections during 2010-2040. Bangkok: NESDB; 2010.

19. Pagaiya N, Khaonuan B, Phanthunane P, Bamrung A. Human resources for health projections for primary health care services in Thailand 2026. J Health Syst Res. 2018;12(2):189-204.

20. Noree T. Health workforce planning: doctors. In: Noree T, editor. Policy options for the human resources for health planning in the next decade. Nonthaburi: Human Resources for Health Research and Development Office (HRDO); 2017. p. 306-32.

21. Sawaengdee K. Health workforce planning: nurses. In: Noree T, editor. Policy options for the human resources for health planning in the next decade. Nonthaburi: Human Resources for Health Research and Development Office (HRDO); 2017. p. 333-72.

22. Jaichuen W. Dentist and dental nurse projection for Thailand in 2016-2026. Health Syst Res. 2018;12(2):221-31.

23. Kesomboon $\mathrm{N}$, Udomaksorn K. Health workforce planning: pharmacists. In: Noree T, editor. Policy options for the human resources for health planning in the next decade. Nonthaburi: Human Resources for Health Research and Development Office (HRDO); 2017. p. 432-93.

24. Prachayasitikul W, Treeratanapaiboon L. Health workforce planning: medical technologists. In: Noree T, editor. Policy options for the human resources for health planning in the next decade. Nonthaburi: Human Resources for Health Research and Development Office (HRDO); 2017. p. 494-507.

25. Kaewsawang S, Luewisetpaiboon S, Theerawutwarawet K, Chaipinyo K. Projection of physical therapy workforce for Thailand health system in the next decade. In: Noree T, editor. Policy options for the human resources for health planning in the next decade. Nonthaburi: Human Resources for Health Research and Development Office (HRDO); 2017. p. 636-56.

26. Chantraket $R$, Stienrut $P$, Laohapan $T$, Sornrung W, Jansorn S. Workforce planning for Thai traditional medicine in the next decade, 2017-2026. J Health Syst Res. 2018;12(2):254-66.

27. Ono T, Lafortune $G$, Schoenstein M. Health workforce planning in OECD countries: a review of 26 projection models from 18 countries. OECD Health Working Papers, no. 62. Paris: OECD Publishing; 2013. https://doi.org/10. 1787/5k44t787zcwb-en. Accessed 2 Apr 2018

28. Yin D, Yin T, Yang $H$, Xin Q, Wang L, Li N, et al. An economic-research-based approach to calculate community health-staffing requirements in Xicheng district, Beijing. Hum Resour Health. 2016;14:70.
29. Murphy GT, Birch S, MacKenzie A, Rigby J. Simulating future supply of and requirements for human resources for health in high-income OECD countries. Hum Resour Health. 2016;14:77.

30. Nigenda G, Munos A. Projections of specialist physicians in Mexico: a key element in planning human resources for health. Hum Resour Health. 2015;13:79.

31. Health workforce Australia 2014. Australia's future health workforce - Oral health - Overview. Canbera: Department of Health; 2014
Ready to submit your research? Choose BMC and benefit from:

- fast, convenient online submission

- thorough peer review by experienced researchers in your field

- rapid publication on acceptance

- support for research data, including large and complex data types

- gold Open Access which fosters wider collaboration and increased citations

- maximum visibility for your research: over $100 \mathrm{M}$ website views per year

At BMC, research is always in progress.

Learn more biomedcentral.com/submissions 